\title{
MENINGKATKAN SELF-EFFICACY DAN KEMAMPUAN BERPIKIR KREATIF SISWA MELALUI MODEL PROJECT BASED LEARNING PADA MATERI KOLOID
}

\section{Improving Self-Efficacy and Creative Thinking Ability Students Through The Project Based Learning Model On Colloidal Material}

\section{Aulia Ulfah", Rusmansyah, Abdul Hamid}

Program Studi Pendidikan Kimia FKIP Universitas Lambung Mangkurat, Jl. Brigjend. H. Hasan Basry Banjarmasin 70123 Kalimantan Selatan Indonesia *email: auliaulfah81@gmail.com

\begin{abstract}
Abstrak. Telah dilaksanakan penelitian tentang meningkatkan self-efficacy dan kemampuan berpikir kreatif siswa melalui model PjBL pada materi koloid di kelas XI MIPA 3 SMA Negeri 6 Banjarmasin dengan 35 orang siswa. Penelitian ini bertujuan untuk meningkatkan (1) keterlaksanaan aktivitas guru, (2) aktivitas siswa, (3) self-efficacy siswa, dan (4) kemampuan berpikir kreatif siswa. Metode yang digunakan adalah penelitian tindakan kelas (PTK) model John Elliot 2 siklus dengan 2 pertemuan disetiap siklusnya. Setiap siklus terdiri dari perencanaan, pelaksanaan tindakan, observasi dan evaluasi serta refleksi. Hasil penelitian menunjukkan terjadi peningkatan (1) keterlaksanaan aktivitas guru dari kategori cukup baik menjadi baik, (2) aktivitas siswa dari kategori cukup aktif menjadi aktif, (3) self-efficacy siswa dari kategori sedang menjadi tinggi, dan (4) kemampuan berpikir kreatif siswa dari kategori cukup kreatif menjadi kreatif.
\end{abstract}

Kata kunci: Self-efficacy, kreatif, PjBL, koloid

\begin{abstract}
The Research has been improved self-efficacy and creative thinking ability through the PjBL model on colloidal material at class XI MIPA 3 with 35 students. The research has been purpose for improving (1) teacher activity, (2) students activity, (3) students self-efficacy, and (4) students creative thinking ability. The research method used a classroom action research (PTK) of John Elliot model, 2 cycle with 2 meetings in all cycle. Each cycle consists of planning, action implementation, observation, evaluation and reflection. The result of research improved (1) teacher activity from category good enough to be good, (2) students activity from category active enough to be active, (3) students self-efficacy from category medium to be high, and (4) students creative thinking ability from category creative enough to be creative.
\end{abstract}

Keywords: Self-efficacy, creative, PjBL, colloidial

\section{PENDAHULUAN}

Pendidikan abad 21 mengharuskan pembelajaran yang berfokus pada guru diubah menjadi berfokus pada siswa (Yusnaeni, Susilo, Corebima, \& Zubaidah, 2016). Berdasarkan Permendikbud No.22 Tahun 2016, Kurikulum 2013 menuntut guru mengembangkan pembelajaran yang dapat merangsang siswaamemiliki kemampuan 4C, yaitu critical thinking, collaboration, communication, serta creative thinking.

Kemampuan berpikir kreatif sangat diperlukan agar siswa bisa bertahan serta beradaptasi di zaman yang keras akan persaingan. Berpikir kreatif merupakan pendukung tercapainya keberhasilan pembelajarn dengan membuat hal yang berbeda

Copyright @ JCAE-Jurnal Tugas Akhir Mahasiswa, e-ISSN 2613-9782

Program Studi Pendidikan Kimia FKIP Universitas Lambung Mangkurat 
dengan yang lain (Murjani \& Hamid, 2016). Kemampuan berpikir kreatif juga dipengaruhi oleh kepercayaan dirinya sendiri/self-efficacy. Menurut Bandura (1997), Self-efficacy akan menentukan bagaimana seseorang bertindak, berpikir, dan memotivasi dirinya sendiri.

Hasil observasi dan wawancra di SMA Negeri 6 Banjarmasin, diperoleh bahwa siswa dinilai memiliki kemampuan berpikir kreatif yang rendah. Mereka belum terbiasa menciptakan ide atau gagasan baru serta belum terbiasa menghasilkan jawaban maupun pandangan yang bervariasi. Diperkuat dengan hasil tes awal kemampuan berpikir kreatif-kritis Yan-Piaw (Filsame, 2008) di kelas XI MIPA 3 SMAN 6 Banjarmasin, dari hasil tes hanya 5 siswa yang tergolong dalam kreatif-kritis, 5 orang tergolong dalam cukup kreatif-kritis, sedangkan 25 orang sisanya masih tergolong kurang kreatif-kritis.

Hasil obsrvasi dan wawancara juga menunjukkan bahwa self-efficacy dinilai rendah karena saat pembelajaran berlangsung siswa cenderung pasif saat belajaar. Ketika diberikan permasalahan, mereka masih ragu dalam menyampaikan pendapatnya. Permasalahan ini perlu dicermati mengingat peran aktif siswa menjadii unsur keterlibatan penuh dalam interaksi pembelajarn agar tidak terjadi kesulitan dalam memahami materi.

Peran aktif siswa dalam proses pembelajaran pada dasarnya berkaitan erat dengan self-efficacy dalam menyelesaikan berbagai permasalahan serta menemukan suatu konsep. Siswa merasa lebih siap untuk berpartisipasi dalam proses pembelajaran jika ia merasa yakin mampu untuk menyelesaikan setiiap permasalahan yang ditemui (Hidayati, Leny, \& Iriani, 2018).

Upaya yang dapat dilakukan agar pembelajaran terlaksana dengan baik yaitu menghadirkan model pembelajaraan yang inovatif, yaitu PjBL. Model PjBL dapat diterapkan pada materi koloid sesuai kompetensii dasar dalam Kurikulum Nasional yaitu membuat makanan atau produk lain yang berupa koloiid atau mengaitkan prinsip koloid. Berdasarkan kompetensi dasar tersebut, siswa dituntut membuat proyek dalam pembelajaran.

Model $\mathrm{PjBL}$ dapat meningkatkan self-efficacy dan kemampuan berpikir kreatif siswa, sejalan dengan penelitian Fitri, Rusmansyah, \& Bakti (2018) bahwa terdapat perbedaan signifikan kemampuan berpikir kreatif dan self-efficacy siswa antara kelas yang menerapkan model PjBL dengan kelas konvensional dengan hasil pada kemampuan berpikir kreatif yaitu t-hitung $>$ t-tabel $(4,28>2,03)$ dan selfefficacy yaitu t-hitung $>$ t-tabel $(3,97>2,03)$.

\section{METODE PENELITIAN}

Penelitian ini menggunakan jenis PTK model John Elliot. Penelitian dilaksanakan pada 9-24 Mei 2019 dengan objek penelitian 35 siswa kelas XI MIPA 3 SMA Negeri 6 Banjarmasin. Teknik pangumpulan data yang dipakai yakni lembar observsi aktivitas guru, aktivitas siswa, kemampuan berpikir kreatif proyek, angket self-efficacy serta tes kemampuan berpikirkreatif siswa.

Data aktivitas guru, aktivitas siswa, serta kemampuan berpikir kreatif proyek diperoleh melalui teknik nontes menggunakan lembar observasi. Data self-efficacy diperoleh melalui teknik angket menggunakan 15 butir pernyataan serta kemampuan berpikir kreatif diperoleh melalui teknik tes menggunakan soal uraian sebanyak 4 butir disetiap akhir siklus. 


\section{HASIL PENELITIAN DAN PEMBAHASAN}

Aktivitas Guru

Terjadi peningkatan hasil obsrvasi aktivitas guru mulai kategori cukup baik menjadi baik.

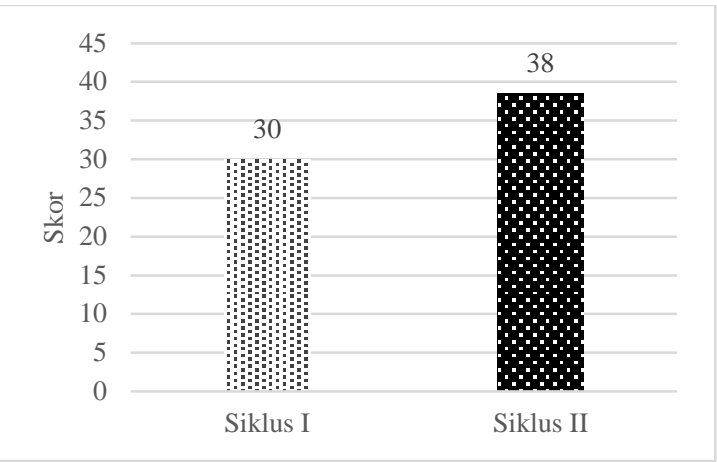

Gambar 1. Hasil observasi aktivitas guru

Masih banyak aktivitas guru yang kurang maksimal di siklus I seperti membimbng serta mementoring siswa sehingga pembellajaran belum maksimal dan belum mencapai peningkatan sesuai harapan. Guru memperbaiki kekurangan disiklus II, berdasarkan hasil refleksi siklus I, seperti memfasilitasi serta lebih membimbing dalam pembuatan proyek. Guru mengorganisir kelas dan memastikan semua siswa ikut dalam penyelesaian proyek.

Menurut Sutirman (2013) kemampuan guru dalam mengorganisir kelas dan prilaku siswa merupakan cara untuk terwujudnya pembelajaran yang berkualitas. Terlihat adanya kemajuan aktivitas guru dari skor 30 menjadi 38,5. Sejalan dengan penelitian Mastulfiah (2017) menyatakan peningkatan aktivitas guru terjadi disetiap pembelajaran terutama pada siklus II.

\section{Aktivitas Siswa}

Terjadi peningktan aktivitas siswa, namun masih terdapat kendala padaa siklus I. Siswa perlu bimbingan guru dalam pembuatan proyek. Menurut Trianto (2011) siswa mengalami kesulitan dalam pembelajaran karena belum terbiasa dengan model pembalajaran baru sehingga aktivitas siswa belum maksimal.

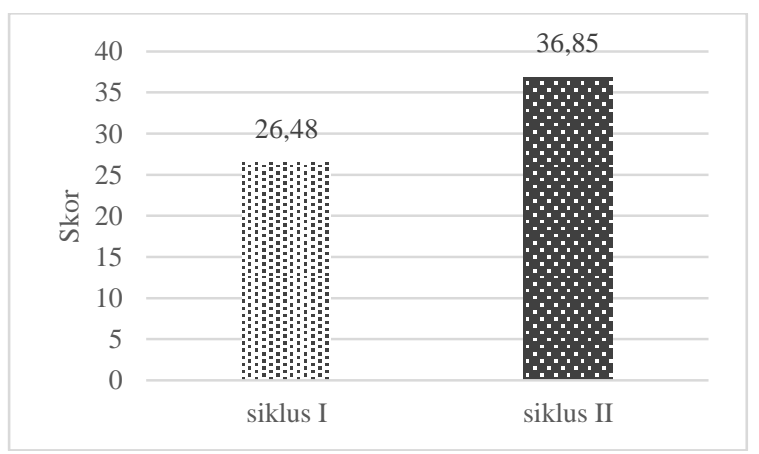

Gambar 2. Hasil observsi aktivitas siswa

Terjadi peningkatn aktivitas siswa dari 26,48 kategori cukup aktif menjadi 36,85 ktegori aktif karena guru membenahi cara mengajar yakni membimbing siswa hingga terbiasa dengan model PjBL. 
Aktivitas siswa akan meningkat selama pembelajaran berlangsung apabila aktivitas guru diilaksanakan dengan efektif dan efisien (Ariani, Hamid, \& Leny, 2015). Penelitian Harbert (2017) juga menyatakan bahwa keberhasilan aktivitas siswa dalam pembuatan proyek secara kreatif dipengaruhi oleh aktivitas pengajar.

\section{Kemampuan Berpikir Kreatif Proyek}

Pembelajaran menggunakan proyek lebih mudah meningkatkan kreativitas. Sejalan dengan penelitian Lubis (2018) menunjukkan bhwa model PjBL dapat meningkatkan kreativitas siswa.

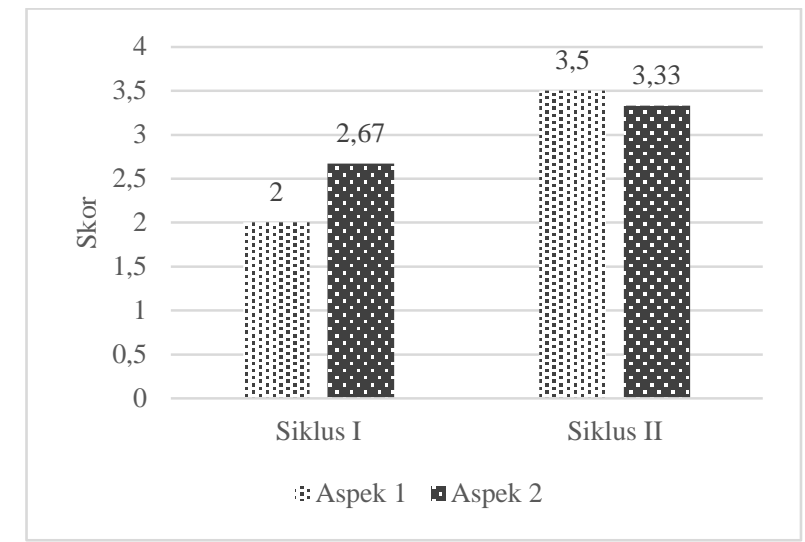

Gambar 3. Perbandingan kemampuan berpikir kreatif proyek

Berpikir kreatif proyek menggunakan model PjBL berdasarkan Gambar 3 mengalami peningkatan dari 4,67 kategori cukup kreatif menjadi 6,83 kategori sangat kreatif. Menurut Sari, Sutikno, \& Masturi (2015), PjBL adalah model pembelajaaran yang membuat siswa aktif selama proses pembelajaran,serta dapat membuat siswamenjadi lebih kreatif.

Diperkuat oleh penelitian Aminullah (2017) yang menyatakan pembelajaran menggunakan proyek dapat meningkatkan berpikir kreatif karena metode pembelajaran bertujuan menghasilkan/menemukan hal baru.

\section{Self-Efficacy}

Siswa pada dasarnya telah memiliki self-efficacynya masing-masing sehingga untuk meningkatkan self-efficacy pada diri mereka, hanya membutuhkan peningkatan yang lebih baik lagi. Indikator self efficacy yang digunakan yaitu (1) Yakin mampu menyelesaikna tugas, (2) Yakin mampu memotivasi dirii untuk melaksanakan tindakan yang akan dilakukan dalam menuntaskan tugas, (3) Yakin bahwa diri mampu berupaya dengn keras, gigih, rajin dalam menuntaskan tugas (4) Yakin bahwa diri mampu bertahan menghadapi halangan serta kendala, (5) Yakin mampu menuntaskan tugas yang diberikan dengan benar. 


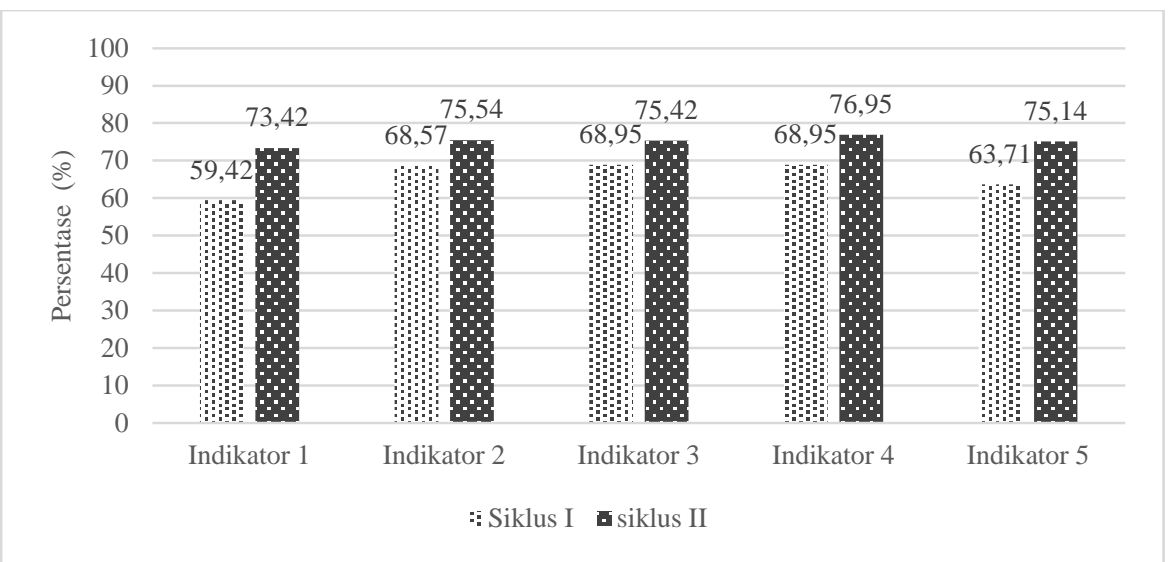

Gambar 4. Perbandingan persentase self-efficacy

Berdasaarkan hasil angket self-efficacy siswa mengalami peningkatan dari rata-rata persntase 65,92 kategori sedang menjadi 75,29 kategori tinggi karena guru memberikan perbaikan tindakan, seperti selalu memberikan motivasi dan penjelasan yang lebih baik agar siswa fokus belajar.

Guru juga memberitahukan siswa bahwa materi yang diajarkan akan mudah dipahami mereka sehingga membuat siswa menjadi lebih tertarik untuk belajar. Sejalan dengan penelitian Maulidah, Rusmansyah, \& Leny (2017) menunjukkan peningkatan self-efficacy siswa pada aspek keyakinan mencapai target yang telah ditentukan menjadi kategori tinggi.

\section{Kemampuan Berpikir Kreatif}

Terjadi peningkatan hasil tes secara keseluruhan dari skor 40,40 kategori cukup kreatif menjadi 60,61 kategorii kreatif karena adanya perbaikan cara guru dalam mengajar. Instrumen tes berpikir kreatif menggunakan 4 butir soal dengan indikator fluence, flexibility, originality, dan elaboration.

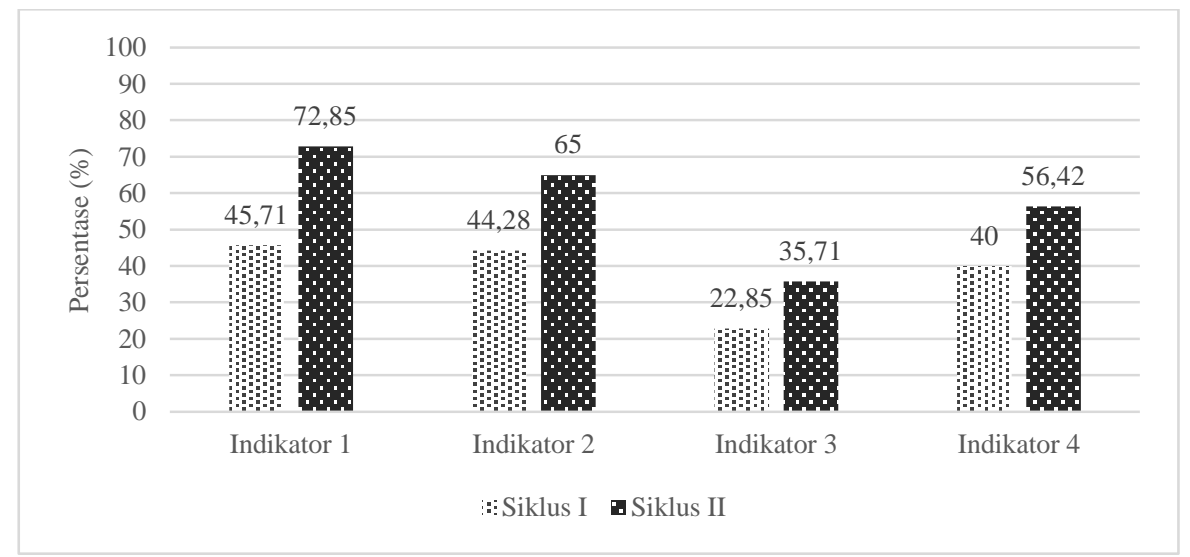

Gambar 5. Hasil tes keterampilan berpikir kreatif

\section{Fluency}

Indikator fluency mengalami peningkatan prsentase dari cukup kreatif menjadi kreatif dikarenakan saat pembelajaran, guru selalu memberikan pertanyaan sehingga siswaa memiliki tugas yang harus dikerjakan, hal ini dapat meningkatkan 
aspek fluency (kelancaran) siswa dalam menghasilkan banyak pertanyaan dan gagasan (Rahmazatullaili, Zubainur, \& Munzir, 2017).

\section{Flexibility}

Indikator flexibility mengalami peningkatan dari cukup kreatif menjadi kreatif, siswa sudah dapat menjawab pertanyaan dengan jawaban bervariasi dan menganalisis masalah. Menurut Wahyu, Rusmansyah \& Sholahuddin (2017) menyatakan bahwa dari kemampuan siswa dalam menyelesaian masalah, dapat melihat keberhasilan indikator flexibility.

\section{Originality}

Indikator originallity mengalami peningkatan dari kurang kreatif menjadi cukup kreatif. Rendahnya presentase pada indikator ini disebabkn penilaian jawaban siiswa dibandingkan secara keseluruhan, hanya jawaban yang benar-benar berbeda dan unik yang mendapatkan skor. Sesuai dengan yang dikatakan Hu \& Adey (2010) indikator originality setiap jawaban pada butir tertentu dibandingkan dngan jumlah total jawaban seluruh siswa.

\section{Elaboration}

Indikator elaboration mengalami peningktan dari cukup kreatif menjadi kreatif. Menurut Antika \& Sulton (2017) langkah penentuan proyek mendukung kemampuan berpikiir kreatif dalam mengembangkan/menambahkan ide sehingga akann menghasilkan ide yang lebih detail (elaboration).

\section{SIMPULAN}

Berdasarkan data hasil penelitian serta pembahasan disimpulkan model PjBL dapat meningkattkan self-efficacy dan kemampuan berpikir kreatif diikuti oleh meningkatnya aktivitas guru dan aktivitas siswa. Adapun untuk saran berdasarkan penelitian ini adalah saat proses pembelajarann, diperlukan pengelolaan waktu yang lebih efektif dan efisien agar dalam penerapan $\mathrm{PjBL}$ bisa terlaksana dengan baik.

\section{DAFTAR RUJUKAN}

Aminullah. (2017). Kajian Penggunaan Metode Pembelajaran Berbasis Proyek (Project Based Learning) dalam Meningkatkan Kemampuan Berpikir Kreatif Matematis. Prosiding Seminar Nasional Pendidik dan Pengembang Pendidikan UMM (43-51). Mataram: Universitas Mahasaraswati Mataram.

Antika, R. N., \& Sulton, N. (2017). Pengaruh Model Project Based Learning pada Mata Kuliah Seminar terhdap Keterampilan Berpikir Kreatif Mahasiswa. Jurnal Pendidikan Biologi Indonesia, 1-10.

Ariani, M., Hamid, A., \& Leny. (2015). Meningkatkan Keterampilan Proses Sains dan Hasil Belajar Siswa pada Materi Koloid dengan Model Inkuiri terbimbing (Guided Inquiry) pada Siswa Kelas XI IPA 1 SMA Negeri 11 Banjarmasin. Quantum : Jurnal Inovasi Pendidikan Sains, 6(1), 98-107.

Bandura, A. (1997). Self Efficacy: The Exercise of Control. New York: W. H. Freeman and Company.

Filsame, D. K. (2008). Menguak Rahasia Berpikir Kritis dan Kreatif. Jakarta: Prestasi Pustakarya.

Fitri, M. A., Rusmansyah, \& Bakti, I. (2018). Pengaruh Model Project Based Learning (PjBL) dalam Pembelajaran Materi Koloid Terhadap Kemampuan Berpikir Kreatif dan Self-Efficacy Peserta didik Kelas XI IPA di SMA Negeri 9 Banjarmasin. Skripsi Sarjana: Universitas Lambung Mangkurat 
Harbert. (2017). Using Critical Thinking Teaching Methods To Increase Student Success : An Action Research Project. Journal of Teaching and Learning in Higher Education, 3 (2).

Hidayati, N., Leny, \& Iriani, R. (2018). Pengaruh Model Pembelajaran Inquiry Based Learning dengan Pendekatan Flipped Classroom terhadap Self Efficacy dan Hasil Belajar Kesetimbangan Ion dalam Larutan Garam. Proceedings of The Innovation of Chemistry Education in Confronting Disruption Era to Build Excellent and Productive Generation (99-107). Banjarmasin: Pendidikan Kimia FKIP ULM.

Hu, W., \& Adey, P. (2010). A Scientific Creativity test for Secondary School Students. International Journal of Science and Education, 389-403.

Lubis, A. F. (2018). Upaya Meningkatkan Kreatifitas Siswa Melalui Model Project Based Learning. PeTeKa (Jurnal Penelitian Tindakan Kelas dan Pengembangan Pembelajaran), 192-201.

Mastulfiah. (2017). Meningkatkan Aktivitas dan Hasil Belajar Siswa pada TK Wardhatussolihin melalui Penggunaan Alat Permainan Edukatif (APE) dalam pembelajaran. Jurnal Langsat, 4(1): 29-34.

Maulidah, A., Rusmansyah, \& Leny. (2017). Meningkatkan Self Efficacy dan Keterampilan Berpikir Kritis dengan Model Pembelajaran Inkuiri Terbimbing Berbantuan Virtual Laboratory Materi Larutan Penyangga Kelas XI IPA 1 SMA PGRI 4. Journal Of Chemistry And Education, 1-10.

Murjani, A., \& Hamid, A. (2017). Meningkatkan Kemampuan Berpikir Kreatif Dan Hasil Belajar Siswa Melalui Model Pembelajaran Generatif Pada Materi Larutan Penyangga. Quantum: Jurnal Inovasi Pendidikan Sains, 7(2), 103108.

Rahmazatullaili, Zubainur, C. M., \& Munzir, S. (2017). Kemampuan Berpikir Kreatif dan Pemecahan Masalah Siswa Melalui Penerapan Project Based Learning. Beta Jurnal Tadris Matematika, 8-13.

Sutirman. (2013). Media \& Model-Model Pembelajaran Inovatif. Yogyakarta: Graha Ilmu.

Trianto. (2014). Mendesain Model Pembelajaran Inovatif, Progresif, dan Kontekstual. Jakarta: Prenadamedia Group.

Wahyu, Rusmansyah, \& Sholahuddin, A. (2017). Meningkatkan Kemampuan Berpikir Kreatif dan Self Efficacy siswa Menggunakan Model Creative Problem Solving Pada Materi Sistem Koloid,. Jurnal Vidya Karya, 32 (1).

Yusnaeni, Susilo, H., Corebima, A., \& Zubaidah, S. (2016). Hubungan Kemampuan Berpikir Kreatif dan Hasil Belajar Kognitif pada Pembelajaran Search Solve Create and Solve di SMA. Prosiding Seminar Nasional Biologi, 443-446. 